\title{
A MÚSICA NA PRÁTICA DOCENTE DO PEDAGOGO: REFLEXÕES SOBRE O ESTÁGIO NA EDUCAÇÃO INFANTIL
}

\author{
MUSIC AND THE GENERALIST TEACHER: CONSIDERATIONS ON PRESERVICE \\ TEACHING IN CHILDHOOD SCHOOLS
}

\section{LA MÚSICA EN LA PRÁCTICA DOCENTE DEL PEDAGOGO: REFLEXIONES SOBRE EL ENSINO EN LA EDUCACIÓN INFANTIL}

Isadora Brezolin Santana

E-mail: isadoraprof@hotmail.com

Vanessa Weber

E-mail: vanewebersm@,gmail.com Universidade Federal de Santa Maria

\begin{abstract}
RESUMO
A música está presente nas escolas de educação infantil, porém, o trabalho com conhecimentos específicos dessa área do conhecimento muitas vezes se torna um desafio para o professor que não é formado em Música. Assim, o objetivo desta pesquisa delimitou-se em compreender como uma pedagoga pode atuar com a proposta da educadora musical Josette Feres, no ensino de música para bebês. Neste artigo, busca-se refletir sobre as possibilidades do pedagogo inserir conhecimentos musicais em sua docência a partir de um relato de experiência de práticas pedagógico-musicais realizadas na disciplina de Estágio Supervisionado na Educação Infantil, do curso de Pedagogia da Universidade Federal de Santa Maria. A organização dessas práticas, realizadas em uma turma de berçário, teve como referência a proposta pedagógico-musical da educadora musical Josette Feres em seu livro "Bebê - música e movimento". Como procedimentos metodológicos para a organização e posterior reflexão sobre as práticas pedagógico-musicais realizadas, foi realizada uma pesquisa-participante, que teve como referenciais teóricos pesquisadores da educação musical, dentre os quais Feres (1998), Brito (2003), Ilari (2009) e Joly (2011). Ao perceber que a inclusão de práticas musicais no estágio com bebês pôde ser realizada, conclui-se que é possível que o pedagogo, com estudo e aprofundamento de conhecimentos pedagógicomusicais, proponha atividades musicais específicas aos bebês durante a prática docente e espera-se que as atividades descritas sirvam de exemplo para professores que buscam incluir conhecimentos musicais em suas aulas na educação infantil.
\end{abstract}

PALAVRAS-CHAVE: Música na educação infantil. Reflexões sobre o estágio. Prática docente do pedagogo.

\section{ABSTRACT}

Music is present in early childhood schools. However, working with specific music knowledge often becomes challenging to the educator who is not licensed for music education. In this paper, we intend to discuss and understand the possibility of the generalist teacher include music knowledge in their teaching, using the propositions for teaching music for babies by music educator Josette Feres. For that end, we reflect on the possibilities of the generalist teacher including music content in their teaching through a report of practices during preservice teaching by a student majoring in Teacher Education in Universidade Federal de Santa Maria. These practices, undertaken in a nursery environment, were based in the music pedagogy proposed by Josette Feres in her book "Baby - music and movement". The research and analysis of the practices were methodologically designed as a participant research and as theoretical underpinnings music educators, such as Feres (1998), Brito (2003), Ilari (2009) and Joly (2011). After realizing that musical practices were satisfactorily included in the nursery preservice teaching, we conclude that it is possible that the general

v.11

n. 3

p. $100-115$

Set. / Dez.

2018 


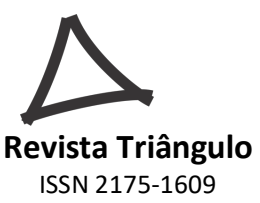

teacher, on studying and deepening their musical pedagogy knowledge, propose musical activities specific to babies during preservice practices and we hope that the activities here described serve as examples for teachers who seek to include musical knowledge in their nursery teaching.

KEYWORDS: Music education for babies. Preservice teaching. General teaching practices.

\section{RESUMEN}

La música está presente en las escuelas de educación infantil, pero el trabajo con conocimientos especificos de esa área a menudo se convierte en un desafio para el profesor que no está formado en Música. Así, el objetivo de esta investigación se delimitó en comprender cómo uma professora de educación infantil puede actuar con la propuesta de la educadora musical Josette Feres, en la enseñanza de música para bebés. En este artículo, se busca reflexionar sobre las posibilidades del pedagogo insertar conocimientos musicales en su docencia a partir de un relato de experiencia de prácticas pedagógico-musicales realizadas en la disciplina de Etapa Supervisada en la Educación Infantil, del curso de Pedagogía de la Universidad Federal de Santa María. La organización de esas prácticas, realizadas en una clase de niños, tuvo como referencia la propuesta pedagógico-musical de la educadora musical Josette Feres en su libro "Bebé - música y movimiento". Como procedimientos metodológicos para la organización y posterior reflexión sobre las prácticas pedagógico-musicales realizadas, se realizó una investigación-participante, que tuvo como referenciales teóricos investigadores de la educación musical, entre los cuales Feres (1998), Brito (2003), Ilari (2009) y Joly (2011). Al percibir que la inclusión de prácticas musicales en la etapa con bebés pudo ser realizada, se concluye que es posible que el pedagogo, con estudio y profundización de conocimientos pedagógico-musicales, proponga actividades musicales específicas a los bebés durante la práctica docente y se espera que las actividades descritas sirvan de ejemplo para profesores que buscan incluir conocimientos musicales en sus clases en la educación infantil.

PALABRAS-CLAVE: Música en la educación infantil. Reflexiones sobre el ensino. Práctica docente del pedagogo.

\section{INTRODUÇÃO}

As ideias para a pesquisa relatada neste artigo surgem de minha participação em uma oficina sobre musicalização de bebês, a partir da qual passei a ter um olhar mais atento sobre esse tema, especialmente em relação a meus alunos. Com esta experiência surgiram alguns questionamentos: como é trabalhada a música com os bebês? Se as professoras ${ }^{1}$ de escolas de educação infantil não são formadas em música, como ensinam esse conteúdo? Quais as atividades musicais e pedagógico-musicais desenvolvidas por pedagogas? Tais questionamentos me acompanharam até eu iniciar o estágio curricular obrigatório do curso de Pedagogia da Universidade Federal de Santa Maria (UFSM), realizado em uma turma de berçário. Depois de muito pensar sobre a música e os bebês, resolvi me desafiar tentando abordar na minha turma a proposta da autora e educadora musical Josette Feres, que apresenta uma proposta de aula de música para bebês.

A partir de meus questionamentos e das observações realizadas na escola antes do estágio, busquei refletir em torno do seguinte problema de pesquisa: Como uma pedagoga, que atua com bebês, pode executar em suas aulas a proposta de musicalização da autora Josette Feres? Neste sentido, como objetivo geral, a pesquisa buscou compreender como uma pedagoga pode atuar com a proposta da educadora musical Josette Feres, no ensino de música para bebês.

Com relação à estrutura, este artigo está constituído por três seções. A primeira apresenta alguns referenciais sobre musicalização de bebês e a estrutura e características da proposta de 
aula de música de Josette Feres. A segunda seção traz os procedimentos metodológicos utilizados para o desenvolvimento da pesquisa e a terceira apresenta os resultados da pesquisa, abordando a análise e reflexões sobre a prática pedagógico-musical desenvolvida durante o estágio.

\section{MUSICALIZAÇÃO DE BEBÊS}

Ao tratar do ensino de música para bebês, tomo como referência a compreensão de que a musicalização infantil "significa desenvolver o senso musical das crianças, sua sensibilidade, expressão, ritmo, 'ouvido musical', isso é, inseri-la no mundo musical, sonoro" (OLIVEIRA, 2001, p. 99). Segundo a mesma autora, este processo "tem como objetivos fazer com que a criança torne-se um ouvinte sensível de música, com amplo universo sonoro" (OLIVEIRA, 2001, p. 99).

Autoras como Brito (2003), Ilari (2009) e Joly (2011) apontam a importância de a musicalização infantil ocorrer também na escola de educação infantil - e não apenas em escolas especializadas de música - podendo auxiliar no desenvolvimento musical, na alfabetização, nas demais áreas do conhecimento, na socialização, etc. Além disso, defendem a musicalização de forma lúdica e prazerosa para a criança, visto que "a criança é um ser 'brincante' e, brincando, faz música, pois assim se relaciona com o mundo que descobre a cada dia" (BRITO, 2003, p. 35). Nesse contexto, os bebês também estão incluídos. Sobre isso Oliveira (2001) afirma que "bebês com menos de dois anos de idade também são capazes de distinguir som e silêncio e, se dermos um instrumento nas mãos deles, eles saberão que, se você perguntar "cadê o som", eles devem tocar o instrumento para ouvirem o som" (OLIVEIRA, 2001, p. 100).

$\mathrm{Na}$ ausência de um professor licenciado em música, é importante que a professora pedagoga envolva a musicalização em suas aulas. Além de momentos dedicados especificamente para a realização de atividades musicais, que busquem desenvolver esta área do conhecimento, a música também pode ser explorada e utilizada em diversos momentos da rotina dos alunos. O professor pode trabalhar a música de forma interdisciplinar com outras áreas do conhecimento, além de pensar em diversos momentos musicais na rotina da sala, como por exemplo, cantar na hora de ir lanchar, dançar na hora de brincar. Para além do canto, outras atividades musicais podem ser desenvolvidas na educação infantil, como a exploração dos sons do próprio corpo e de materiais sonoros diversos, jogos que envolvam sons e gestos e contação de histórias sonorizadas².

As histórias sonorizadas são uma possibilidade para o trabalho com música de fácil acesso para professoras de educação infantil e anos iniciais, pois conhecem o contexto de suas turmas, sendo possível identificar os elementos e temas que lhes são mais significativos e que podem aguçar ainda mais a imaginação e a criatividade, contribuindo para a construção da história sonorizada. Além disso, nesse tipo de atividade não se fazem necessárias habilidades vocais ou o uso de instrumentos musicais convencionais, podendo ser utilizados a voz, o corpo ou objetos sonoros. (WERLE, 2011, p. 90) 
Pensando especificamente na musicalização de bebês, Josette Feres se torna referência, devido sua experiência como educadora musical e às suas publicações a respeito do tema. Para a educadora, o principal objetivo da musicalização infantil é desenvolver na criança, o prazer de ouvir e fazer a música. A partir da experiência de musicalização infantil em sua escola de música, publicou o livro "Bebê, música e movimento: orientação para musicalização infantil", no qual apresenta diversos objetivos para as aulas de música para bebês:

Estimular maior ligação afetiva entre a mãe (ou o adulto que cuida da criança) e o bebê. Proporcionar à criança momentos de prazer junto a quem ama. Contribuir para resgatar o nosso patrimônio cultural, utilizando canções folclóricas e populares na aula. Dar modelos de interação musical, fornecendo um repertório para a mãe cantar e brincar com o filho. Proporcionar à criança um ambiente onde terá maior liberdade para criar. Estimular o canto e a fala. A criança aprende a cantar ao mesmo tempo que aprende a falar. Dar oportunidade à criança de ter contato com outras pessoas numa atmosfera expressiva e agradável. Ensinar a criança a representar regras e conhecer limites. Desenvolver a musicalidade, sensibilidade, percepção auditiva, psicomotricidade, senso rítmico e sociabilidade. (FERES, 1998, p. 13-14).

A autora propõe aulas de musicalização de bebês realizadas uma vez por semana, no período de trinta minutos, sendo que o professor deverá saber o nome dos alunos, desde o primeiro contato com eles. O ambiente no qual a aula será trabalhada deve ser espontâneo, alegre e descontraído, com uma sala de aula, espaçosa, clara e bem ventilada, com armários para guardar o material didático. "Não existe uma idade mínima para realizar este trabalho, se desenvolvido numa creche, hospital, mini-maternal ou mesmo em casa" (FERES, 1998, p.15). A educadora propõe que um adulto sempre acompanhe a criança, pois se a criança for muito pequena e ainda não andar poderá fazer os exercícios de locomoção no colo de algum adulto que esteja lhe acompanhando. Como "o tempo de desenvolvimento é diferente de uma criança para a outra" (FERES, 1998, p.16), a aula terá que ser adaptada para as diferentes faixas etárias dos alunos.

Segundo a educadora, é ideal que o professor que irá trabalhar com musicalização de bebês possua uma voz acurada e agradável para cantar canções e dizer parlendas expressivamente, seja espontâneo e divertido, para poder fazer atividades, movimentos e danças com maior liberdade, e sinta-se bem e à vontade entre as crianças. A proposta de Josette Feres é voltada para crianças a partir de oito meses de idade acompanhadas de um adulto e a educadora entende que não é aconselhável que se ajude a criança a bater o ritmo ou se ensine a segurar um instrumento, visto que se espera que a própria criança desenvolva por si mesma seu sentido do ritmo. Com relação a conteúdos musicais, as propriedades que compõe o som são exploradas informalmente, não havendo cobranças pelo professor e "as músicas são apresentadas com variações de tempo, intensidade, altura e timbre, apenas para acompanharem mais rápido ou mais lento, mais forte ou mais leve etc.” (FERES, 1998, p.17).

Quando os pais ou os professores forem cantar para uma criança, é aconselhável que fiquem em frente a ela, sempre. Além disso, a educadora propõe que, durante as aulas, nos momentos de término de alguma atividade, o brinquedo ou instrumento que estava sendo

\begin{tabular}{|l|l|}
\hline v.11 & $\mathrm{n} .3$ \\
\hline
\end{tabular}


utilizado deve ser guardado. Caso a criança não queira devolvê-lo, não é forçada a isso, visto que cada vez que mudar a atividade da aula, ou surgir outro brinquedo, a criança devolverá o primeiro espontaneamente.

Segundo Feres (1998), os materiais didáticos também são de grande importância na aula de música para bebês e podem ser: chocalhos, castanholas, bichinhos de pelúcia, cavalinho de cabo de vassoura, bambolês, colheres de pau, tambores feitos de potes de sorvete, tubos de filmes fotográficos, canudos de papelão, latas de talco, entre outros.

A autora propõe que a aula seja dividida em 8 momentos: 1) Brinquedo livre; 2) Canto de entrada; 3) Hora do canto: expressão corporal, percussão corporal, brinquedo projetivo, movimento sem locomoção, movimento com locomoção, exercícios de socialização; 4) Parlendas, rimas e brincadeiras musicais; 5) Marchas, danças e cirandas; 6) Conjunto de percussão; 7) Relaxamento e estiramento; e 8) Canto de despedida.

O brinquedo livre será realizado antes de iniciar propriamente a aula, com instrumentos e brinquedos, e é de grande importância para os bebês, pois é o momento em que os mesmos podem explorar e brincar com o material da aula livremente.

Na sequência, virá o canto de entrada, que representa o início da aula. Sempre se começa a aula com uma canção, desejando que todos sejam bem-vindos. O professor canta, se dirigindo a cada aluno, lhe estendo a mão e cantando seu nome. Este canto de entrada será sempre o mesmo, o ano todo, pois é um aviso que a aula vai começar.

A hora do canto é composta por vários momentos: expressão corporal, percussão corporal, brinquedo projetivo, movimento sem locomoção, movimento com locomoção e socialização. A hora do canto traz canções simples, curtas e de vocabulário fácil, que se referem a animais, meios de transporte e cenas da vida infantil.

Uma nova canção é ensinada a cada aula, mas as crianças não aprendem logo na primeira vez. É necessário que o professor cante várias vezes, e, por diversas aulas, até que a melodia seja assimilada. Cada canção é repetida pelo menos três vezes na mesma aula. O professor escolhe, também, uma das canções de aulas anteriores para recordar. (FERES, 1998, p. 29).

$\mathrm{Na}$ musicalização para bebês, também se trabalha o folclore brasileiro, através da utilização de parlendas, rimas e brincadeiras musicais, fazendo "as crianças acompanharem o ritmo, batendo palmas, marchando, rodando, balançando o corpo e muitas atividades terminam com um abraço gostoso" (FERES, 1998, p. 53). No momento das marchas, danças e cirandas são cantadas canções de roda com coreografias de danças muito simples, e, na maioria das vezes, inspiradas na própria letra das músicas.

$\mathrm{Na}$ musicalização de bebês, a autora propõe também o momento do conjunto de percussão, no qual "não há divisão de naipes, isto é, todos tocam instrumentos iguais. As crianças acompanham as músicas como querem e não há interferência em nada. [...] Em sua maioria são instrumentos de bater (tambores, clavas) e de sacudir (chocalhos, guizos)" (FERES, 1998, p. 63).

Após todos esses tipos de exercícios e atividades musicais, é necessário o momento do relaxamento e estiramento, ou seja, um tempo para que todos os bebês se acalmem. Essa é uma parte simples, mas necessária. Pode-se cantar um acalanto e escurecer a sala, tornando o 
ambiente propício para o relaxamento. Após o relaxamento, chega a hora da finalização da aula, a qual é realizada com o canto de despedida. O canto de despedida tem a mesma forma do canto da entrada, ou seja, é o mesmo durante todo o ano e serve como aviso de que a aula terminou.

\section{PROCEDIMENTOS METODOLÓGICOS}

Ao buscar compreender como uma pedagoga pode atuar com a proposta da educadora musical Josette Feres, no ensino de música para bebês, a abordagem qualitativa se mostrou apropriada. As práticas pedagógico-musicais sugeridas por Feres (1998) foram planejadas e realizadas no momento em que cursava a disciplina de Estágio Curricular do curso de Pedagogia da UFSM. Para a realização e análise das práticas vivenciadas no estágio, optei por realizar uma pesquisa-participante, a partir da qual minhas atitudes e observações, irritações, impressões e sentimentos, tornaram-se dados para mim mesma, me fizeram refletir e interpretar o contexto desta pesquisa (FLICK, 2009).

Segundo Oliveira (2012), "tanto na pesquisa participante como na pesquisa-ação é de fundamental importância o envolvimento dos pesquisadores(as) nas comunidades em que se realiza o processo de estudo e pesquisa" (p. 75). Neste sentido, fiz a escolha de realizar esta pesquisa sendo um elemento dela. Realizei o estágio em um centro de educação infantil, da cidade de Santa Maria, no qual trabalhava há um ano e meio com uma turma de berçário. A turma possuía 23 bebês, com a faixa etária entre um ano a dois anos.

As atividades musicais realizadas junto aos bebês fazem parte da proposta de musicalização infantil de Josette Feres. Como mencionado anteriormente, na proposta de Josette Feres a aula é dividida em oito momentos, porém, como durante o estágio precisei desenvolver atividades que envolvessem outras áreas do conhecimento, além da música, busquei realizar um momento ou atividade proposta pela autora por dia. Assim, ao longo do estágio realizei sete dias de atividades pedagógico-musicais para os bebês, trabalhando especificamente com atividades e canções dos seguintes momentos: canto de entrada; expressão corporal; percussão corporal; movimento sem locomoção; movimento com locomoção; parlendas, rimas e brincadeiras musicais; e brinquedo projetivo.

Os dados da pesquisa foram produzidos, portanto, a partir de minha prática pedagógica com os alunos. Após as aulas em que eu realizava as atividades musicais, escrevia o relatório em meu diário de pesquisa, no qual eu descrevia o que percebia dos alunos e como tinha sido a atividade. Para maior compreensão do leitor sobre minhas análises e reflexões, trechos deste diário de pesquisa serão trazidos ao longo do texto em itálico. Na próxima seção, apresento os resultados desta inserção das atividades musicais propostas por Josette Feres durante o período de estágio. Busco trazer reflexões sobre as práticas realizadas, juntamente com o referencial teórico que fundamenta esta pesquisa.

\section{ANALISANDO A PRÁtiCA DOCENTE NO ESTÁGIO CURRICULAR OBRIGATÓRIO}




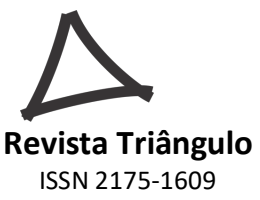

Ao fazer uma análise da minha formação profissional percebo que no estágio curricular obrigatório tive a oportunidade de me enxergar como professora da Educação Infantil, e, principalmente, professora de Berçário. Como mencionado anteriormente, já tinha contato com o centro de educação infantil no qual realizei o estágio, pois estava inserida no mesmo como estagiária da empresa $\mathrm{CIEE}^{3}$. Com muitos questionamentos, resolvi me desafiar e então escolhi a turma de Berçário II para ser a minha turma do estágio curricular obrigatório do curso de Pedagogia, mesma turma em que atuava como professora pelo CIEE.

Ao perceber que a música era pouco trabalhada na Educação Infantil, menos ainda na turma de Berçário, busquei ampliar meus conhecimentos acerca dessa área do conhecimento e decidi inserir atividades musicais nas aulas desenvolvidas para o estágio, pois neste momento teria orientações e apoio da professora responsável pela disciplina de Estágio Supervisionado na Educação Infantil e, referente à música, da professora que orientava meu Trabalho de Conclusão de Curso, professora da disciplina de Educação Musical no Curso de Pedagogia.

Optei por desenvolver, observar e analisar a proposta da educadora musical Josette Feres, por trazer sugestões bem explicadas e exemplificadas de como seria uma aula de musicalização para bebês. A autora propõe que a aula seja dividida em partes, e como eu não tinha muito tempo por dia com os alunos, resolvi fazer uma atividade por dia, na sequência, para que posteriormente eu pudesse analisar as atividades que realizei.

Apesar de já conhecer a escola e o contexto da turma do berçário no qual realizei o estágio este foi um período de muitos desafios em minha vida acadêmica, pois nunca havia planejado para bebês. Deixar de ser estudante para ser professora regente de uma turma também foi desafiador e me trouxe tensões ao planejar para uma turma que eu não tinha experiência.

A inserção profissional no ensino, como comentamos, é o período de tempo que abarca os primeiros anos, nos quais os professores realizarão a transição de estudantes para docentes. É um período de tensões e aprendizagens intensivas em contextos geralmente desconhecidos e durante o qual os professores iniciantes devem adquirir conhecimento profissional além de conseguirem manter certo equilíbrio pessoal. (MARCELO GARCIA, 2010, p.28)

O berçário exige muito dos professores que nele atuam, pois cada aluno tem as suas especificidades, necessitando de higiene, sono, comida, em momentos diversos uns dos outros. Cada um tem uma individualidade e suas necessidades, em momentos diferentes, por isso, ser professora de berçário foi para mim um dos maiores desafios da Educação Infantil, como descrito em meu diário de pesquisa:

Percebo que essa turma tem diferentes necessidades e vai me desafiar muito na regência. São alunos com características muito diferentes, com vivências distintas, com realidades muito diversificadas e que precisam muito mais de atenção, carinho e trocas afetivas do que aprender conteúdos. (Diário de pesquisa $)^{4}$

Percebo que a visão do professor e a importância que ele dá para determinada turma fará diferença no processo de ensino e aprendizagem, pois conhecer os alunos, suas famílias e minimamente o seu contexto de vida, lhe ajudará a analisar e desenvolver um trabalho 
pensado e voltado para os alunos, fazendo assim com que eles aprendam mais facilmente o que o professor quer transmitir e lhe ensinar.

\subsection{A proposta da Josette Feres na docência do Berçário IIA}

Após o estudo da proposta de musicalização de bebês passei a planejar e decidir quais atividades e momentos musicais desenvolveria com a turma. Devido à organização dos horários do berçário, percebi que não conseguiria adicionar o canto de despedida em meu planejamento, pois seguíamos uma rotina na qual depois do almoço os alunos iam diretamente para o momento do "soninho". Este seria o período ideal para a realização dessa atividade específica, mas não conseguia realizá-la em função de que os bebês dormiam logo após o almoço. Assim, quando acordavam meu horário de estágio já havia terminado.

O primeiro momento da aula descrita por Josette Feres representa o brinquedo livre, no qual o bebê tem liberdade para explorar e brincar com brinquedos sonoros. Durante o estágio, esta atividade não foi realizada em dias específicos, pois a atividade de brincar livremente ocorria em todas as manhãs. Neste momento os alunos brincavam com brinquedos da sala de aula, como mordedores, bonecas e carrinhos. Josette Feres propõe que esse momento seja realizado com brinquedos que produzam sons e que sejam explorados ao máximo pelas crianças, sem interferência dos professores. Na sala não havia nenhum brinquedo ou objeto musical, mas em alguns momentos os alunos transformavam o que tinham de brinquedos em objetos sonoros, batendo no chão ou em alguma superfície plana fazendo barulho e explorando diferentes timbres.

Assim como na proposta de Josette Feres, na qual o momento do brinquedo livre acontece antes de todas as aulas, durante o estágio não defini dias específicos para realização desta atividade, pois este momento acontecia em todos os dias antes de iniciarmos a aula. Mantive esse momento diário, pois acredito que brincar desenvolve muitos benefícios nos bebês, como explorar a imaginação, se perceber e perceber o outro enquanto criança, brincar de faz de conta, desenvolvendo assim diversos saberes da criança.

Apesar da escola não contar com brinquedos sonoros e musicais, ao realizar esse momento de brinquedo livre pude observar inúmeras cenas em que as crianças se envolviam com o som dos brinquedos, como relatado em meu diário de pesquisa.

[...] um aluno sozinho com um brinquedo, sentado na cadeira e brincando sobre a mesa. Chega uma colega que também estava com seu brinquedo, brincando sozinha e senta-se ao lado deste colega. Assim vão chegando mais e mais alunos ao redor daqueles dois que ali estavam sozinhos até então. Todos os alunos com brinquedos nas mãos, uma delas bate o brinquedo na mesa. Todos os alunos se olham e começam a bater o brinquedo na mesa. No começo sem pulso e sem ritmo, até que uns segundos depois estão todos batendo em um mesmo pulso, em uma linda sincronia. (Diário de pesquisa)

A partir dessa vivência, percebo a importância dos professores proporcionarem o momento do brinquedo livre aos seus alunos, visto que este momento contribui tanto no 
desenvolvimento quanto na aprendizagem dos mesmos. Como pude perceber não é preciso, necessariamente, ter instrumentos musicais ou brinquedos que produzam sons para este momento, pois os alunos criam seus próprios sons, mas brincando livremente.

Também é importante que o professor pedagogo tenha consciência que a musicalização vai além da exploração sonora pelos bebês, pois há uma "infinidade de atividades que vão além do cantar com os bebês, como o brincar com a voz explorando timbres, alturas e intensidade" (CORREA, 2012, p. 9).

Seguindo o momento com o brinquedo livre, após os alunos já terem chegado à sala de aula e socializado com os colegas e professoras, realizei o momento do canto de entrada. $\mathrm{O}$ canto de entrada (FERES, 1998) é feito no momento de recepção dos alunos. Cantamos para dar boas vindas, para saudar com um "bom dia", dirigindo-se a cada um dos alunos. Realizei essa atividade durante o estágio por diversas vezes, pois desde a primeira vez que cantei "Alô, bom dia" ${ }^{5}$ para os alunos, eles sempre me pediam para cantar em todas as nossas rodas de conversas.

Ao realizar esta atividade, meu principal objetivo era que os alunos realmente se saudassem, pois a turma era agitada e os bebês passavam todo o tempo brigando e gerando conflitos. Nesse contexto, eu queria que eles sentassem e fizéssemos um canto de entrada para começar a manhã calmamente, sem brigas. Então conforme eu ia cantando a música que fala o nome de cada aluno, eu ia cumprimentando os alunos, e, vendo-me fazer isso, os alunos saudavam os colegas da mesma forma.

Realizei o canto de entrada quase todos os dias durante o estágio, pois pude perceber que quando eu começava a aula cantando algumas músicas e entre elas as que saudavam os colegas dando-lhes bom dia os alunos passavam a manhã mais calmos, mais tranquilos. (Diário de pesquisa).

Além dos benefícios que percebi em minha turma de estágio, Ilari e Agnollo (2005) demonstram a importância do canto com as crianças e afirmam que "o ato de cantar, espontaneamente ou de forma dirigida em sala de aula, pode ativar os sistemas da linguagem, da memória, e de ordenação sequencial, sistemas que são vitais para o desenvolvimento cognitivo infantil” (ILARI; AGNOLLO, 2005, p. 1).

Conforme já mencionado, meus alunos do estágio tinham mudanças de comportamento conforme certas atividades desenvolvidas com eles. Além do canto de entrada que modificou bastante o comportamento das crianças, fizemos atividades que eles gostaram muito e me pediram que eu repetisse por diversas vezes. Como exemplo, cito o momento da expressão corporal, que faz parte de um conjunto de atividades que a educadora musical Josette Feres propõe para a hora do canto. Além da expressão corporal, no momento da hora do canto, podem ser realizadas atividades como: percussão corporal, brinquedo projetivo, movimento sem locomoção, movimento com locomoção, socialização (FERES, 1998).

A atividade de expressão corporal possibilitava a execução de movimentos expressivos através das músicas. Percebo que esta fase em que os alunos se encontravam é um momento importante, pois como não se utilizavam da expressão verbal, necessitavam se comunicar com o mundo pela expressão corporal. A esse respeito, Farias (2009) aponta que

\begin{tabular}{|l|l|l|l}
$\mathrm{v} .11$ & $\mathrm{n} .3$
\end{tabular}


[...] as crianças se movimentam desde que nascem adquirindo cada vez maior controle sobre seu próprio corpo e se apropriando cada vez mais das possibilidades de interação com o mundo. Engatinham, caminham, manuseiam objetos, correm, saltam, brincam sozinhas ou em grupo, com objetos ou brinquedos, experimentando sempre novas maneiras de utilizar seu corpo e seu movimento. Ao movimentarem-se, as crianças expressam sentimentos, emoções e pensamentos, ampliando as possibilidades do uso significativo de gestos e posturas corporais. (FARIAS, 2009, p. 19)

Sendo assim, o movimento através da expressão corporal desenvolve a motricidade, a afetividade e a mente dos alunos. No estágio, propus às crianças que trabalhássemos a música "Pela rua abaixo" "FERES, 1998). Ouvimos e cantamos uma vez essa música trabalhando a intensidade, em tom normal, depois cantamos bem forte e, posteriormente, cantamos bem fraco. Por fim, retirei a música do som, deixando somente as vozes. Ao cantarmos a música, dançamos conforme a letra, colocando a mão na testa e a outra na barriga, caminhando pelo espaço da sala de aula. Meu objetivo com essa música era trabalhar a expressão corporal e a intensidade, do forte ao fraco com os alunos.

Executei essa música como planejada duas vezes com os alunos. Na primeira vez, eles ouviram e somente dançaram da forma deles, já na segunda vez, eu executei a música fazendo gestos conforme a letra e eles dançaram junto comigo: "uma mão na testa e a outra na barriga". O trabalho com a intensidade não saiu como eu havia planejado, pois os alunos cantaram as duas vezes da mesma maneira, não distinguindo diferenças de intensidade dos sons. Os alunos não tinham muito acesso a música, com isso, concluo que eu deveria ter trabalhado mais músicas, em todos os momentos do meu estágio, e por mais vezes trabalharmos a intensidade do som, pois acredito que não perceberam essas diferenças devido a pouca vivência com esse tipo de atividade. Apesar de não conseguir atingir meu objetivo musical com os alunos nessa canção, percebi que os alunos adoraram a atividade, como descrito em meu diário de pesquisa:

Os alunos não tinham acesso às músicas da Josette Feres, eles nunca tinham ouvido, mesmo assim adoraram e pediram que eu repetisse mais vezes, e assim eu farei durante todo o restante do estágio. Eles gostaram muito de dançar conforme o que dizia a letra da música, e agora toda a vez que eles ouvem alguma música, tentam fazer o que nela diz. (Diário de pesquisa)

Brito (2003) aponta que "som é movimento, gesto, e por isso, nada mais claro do que sua integração com o movimento corporal” (p.145). Sendo assim, os alunos estão sempre em expressão corporal quando se movimentam e quando estão em integração com um som.

Durante o estágio curricular obrigatório, executei muitas atividades com os alunos da turma na qual eu fui regente, sendo muitas dessas de movimento, de gestos e de sons. Mas de todas as atividades realizadas a percussão corporal, conforme é proposta por Josette Feres, foi a que eu mais gostei de fazer com os alunos. Por meio dela, pude perceber que "a criança imita os demais e cria suas próprias reações: balança o corpo, bate palma, vira ou levanta a cabeça" (BRASIL, 2008, p. 29). Tudo que eu fazia como exemplo para os alunos eles imitavam e estavam sempre alegres, se divertindo. 

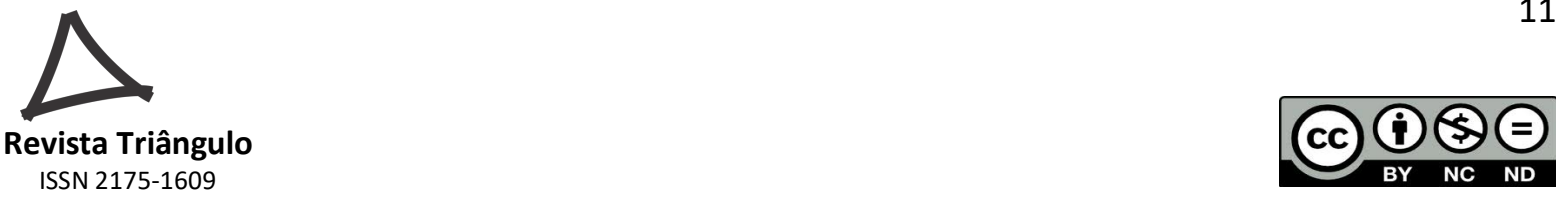

No momento de percussão corporal, eu propus aos alunos que cantássemos duas músicas do livro de Josette Feres: "Palminhas" 7 e "Palma, palma, palma" ${ }^{8}$, e então sentássemos no tapete. Cantamos mais de uma vez, alternando a intensidade e a altura dessas músicas. O meu objetivo foi perceber se os alunos me acompanhariam e entenderiam as mudanças de altura (grave e agudo) que ocorreriam nas músicas.

A música "Palminhas" os alunos já conheciam, pois cantavam comigo e com a outra professora, então não teve nenhum problema, bem pelo contrário, eles adoram e sempre querem que a gente cante mais vezes fazendo essas alterações de intensidade e altura na música, pois os alunos acham divertido cantar dessas formas diferenciadas. A música "Palma, palma, palma" os alunos também já conheciam e adoram, dançando toda a vez que a ouvem. Os objetivos eram os mesmos para as duas músicas, sendo que nessa segunda música, os alunos não entenderam a diferença que ocorria nela. Mesmo assim, trabalharam percussão corporal, batendo as palmas e batendo os pés, como ensina a música. (Diário de pesquisa)

Além da percussão corporal, realizei um momento de brinquedo projetivo, que representa o momento em que "a criança faz o papel do adulto e se projeta no brinquedo fazendo-o andar, pular ou dançar" (FERES, 1998, p. 39). Segundo a educadora musical, essa parte da aula é bastante utilizada em casa pelas crianças enquanto brincam sozinhas. A proposta da Josette Feres é feita em uma aula com o auxílio dos pais, onde cada criança é acompanhada pelo seu responsável. Sendo assim, nesse momento da aula, o adulto faz a atividade e a criança reproduz em casa o que aprendeu na aula. Mas no meu estágio eu não tinha esse acesso a tantos adultos assim, pois era somente eu, a professora regente e mais uma auxiliar para todos os alunos, então fiz com eles uma atividade em que cada aluno tinha que ter uma boneca ou boneco em mãos para que pudéssemos executar a atividade, a qual foi descrita em meu diário de pesquisa:

Convidei os alunos a sentarem no tapete com seus bonecos e suas bonecas no colo. Primeiramente ensinei a eles a música 'Marcha Polichinelo", cantamos umas cinco vezes e depois eu expliquei a eles como iríamos fazer. - Cada um com seu brinquedo vai pegá-lo pelas mãos e vamos saltar, e saltar mais uma vez, depois vamos andar com eles quatro passos pelo tapete, e assim faremos quatro vezes, depois iremos largar o brinquedo e bater três vezes palmas. Mas eu lhes expliquei e mostrei a eles como deveriam fazer. Brincamos umas quatro vezes assim, pois nas duas primeiras não deu muito certo, até que eles compreenderam como seria. Só não repetimos mais vezes, pois a rotina é muito rígida e não temos tempo sempre para o que queremos. (Diário de pesquisa)

Os alunos compreenderam o que eu quis ensiná-los com o brinquedo projetivo e depois muitas vezes durante o estágio os presenciei brincando, cantando e reproduzindo a nossa atividade. Foram situações assim de reconhecimento que eu vivi que me motivaram para cada vez procurar mais atividades diferenciadas e me empenhar sempre mais para os meus alunos estarem felizes e realizados com a escola. 

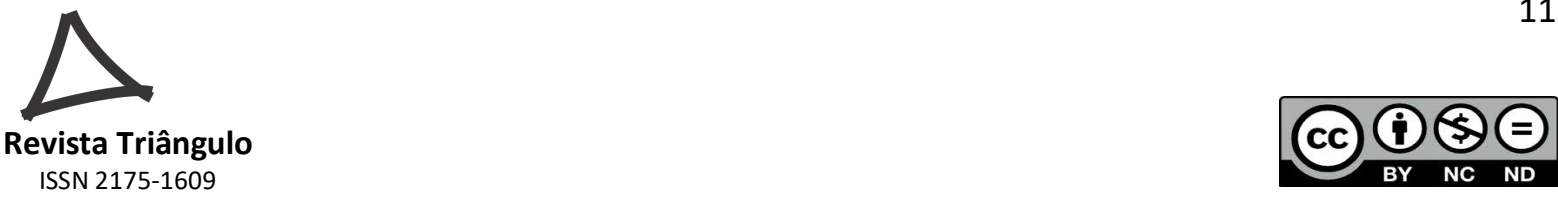

Para trabalhar o momento do movimento sem locomoção cantamos a música "Serra aqui, serra ali" ${ }^{10}$. Em uma rodinha, ficamos de mãos dadas e fizemos movimentos com os braços, para frente e para trás. Trabalhei a intensidade, alternando o canto forte, com um cantar fraco da música. Nesse momento também trabalhei a altura, cantando com a voz bem grossa (grave) e depois bem fininha (agudo). Os alunos adoraram essa música e gostaram muito de dançar e brincar em roda, pois não estavam habituados a este tipo de atividade.

Quando percebi que os alunos gostaram da atividade anterior, eu já imaginava que a próxima que eu faria com eles daria muito certo também. Então lhes apresentei o movimento com locomoção, momento no qual "as canções acompanham as marchas, os saltos, os galopes (no cavalinho de cabo de vassoura), passeios de barco e de trolinho (dentro de um bambolê) ou passeio no carro do papai (usando um bastidor de bordar como volante" (FERES, 1998, p. 44).

Como eu não tive nenhum suporte de instrumentos musicais durante o estágio e a pesquisa, tive que procurar outros objetos para realizar as atividades que eu havia planejado com os alunos. Brito (2003) menciona que "podem-se confeccionar objetos sonoros com as crianças, introduzir brinquedos sonoros populares, instrumentos étnicos, materiais aproveitados do cotidiano" (BRITO, 2003, p. 64). Assim, aproveitei que na escola havia algumas argolas forradas com papel laminado, que foram usadas para a apresentação final do ano anterior e estavam guardadas sem ninguém utilizar e peguei para realizar as minhas atividades.

Entreguei as argolas aos alunos, deixei que eles explorassem aquele material que era desconhecido e depois propus que cantássemos a música "Carrinho do papai" "l e dançássemos com as argolas, como se fosse a direção do carro do papai. Expliquei tudo isso a eles e então fizeram bem direitinho. Adoraram a música e a forma em que brincamos, e eu gostei mais ainda de como se desenvolveu a atividade, que os alunos aprenderam se divertindo. (Diário de pesquisa)

Como os alunos gostaram muito dessa atividade, eu a repeti no mínimo uma vez por semana durante o estágio. Conforme íamos cantando e dançando, eu ia apresentando um dos parâmetros musicais aos alunos, que foi a intensidade. Conforme eles iam aprendendo a música eu dificultava um pouco pedindo que cantassem bem forte e depois bem fraco. No início do estágio quando eu fui desenvolver atividades com parâmetros musicais, os alunos não compreendiam totalmente o que eu queria ensinar, mas com o passar dos dias eles foram aprendendo e com essa atividade de movimento com locomoção eles aprenderam e adoravam quando eu pedia para eles mudarem a intensidade da música.

Segundo Feres (1998), são exercícios de socialização guardar ou devolver o material da aula, cumprimentar pessoas e mandar beijinhos, etc. Esse tipo de atividade era realizado diariamente com a turma, portanto não houve dias específicos para trabalharmos a socialização. Percebo que com relação a esses exercícios brincamos, rimos, choramos, aprendemos, nos divertimos juntos, socializando com tudo e com todos, interagindo o tempo todo.

Pensando mais atentamente ao repertório, trabalhei com os alunos músicas conhecidas por eles e músicas de quando eu era criança, como, como por exemplo, "Atirei o pau no gato" e 
"Marcha soldado". Com essas músicas tive a possibilidade de brincar como eu brincava quando estava na idade dos meus alunos, na Educação Infantil, com a minha professora. Assim, resgatei duas atividades do meu passado e tentei realizar com meus alunos.

Na música "Atirei o pau no gato" fizemos uma roda de mãos dadas e ficamos rodando toda a música até que a letra diz "miau", momento em que todos fomos ao chão. Ao cantar "Marcha soldado", ficamos caminhando pelo espaço da sala com a mão na cabeça, fazendo posição de continêncial'. (Diário de pesquisa)

Os alunos conheciam essas músicas, mas algumas vezes quando a música ainda lhes é desconhecida "eles passam por vezes a imitar o adulto, e aos poucos com canções curtas, repetições, rimas e cantos cumulativos, eles passam a acompanhar e cantar trechos sozinhos" (CORREA, 2013, p. 223).

Ao finalizar o período do estágio, percebi que ensinar brincando é a melhor forma de aprender em qualquer área do conhecimento e na música não é diferente. Correa (2013) fala sobre a importância de o professor explorar o brincar musical em sala de aula. "Brincar porque se faz sem a intenção e preocupação com a técnica e musical porque as ações permeadas por sons intencionais, das crianças com elas mesmas e delas com o que lhes proporcionam o ambiente, o outro, os objetos, a criatividade, os professores" (CORREA, 2013, p. 21).

\section{CONSIDERAÇÕES FINAIS}

Ao finalizar o período de estágio supervisionado do Curso de Pedagogia e a análise das práticas realizadas na turma de berçário percebo que "estar com bebês é uma experiência que nos desafia a cada dia" (COUTINHO, 2013, p. 9). Primeiramente pela comunicação, pois eles ainda não se comunicam com a fala, nem com a escrita, apenas através do corpo, com choros, olhares e gestos, cabendo ao professor ter vontade, disponibilidade, conhecimento e interesse para interpretar o que se passa com esses bebês.

Como segundo desafio, percebo que para trabalhar com os bebês, é necessário que o educador esteja inteiramente disponível para essa relação que irá se construir, pois será o adulto que fará todas as intervenções de socialização desses alunos, tanto com outros adultos, com outras crianças e até mesmo com objetos e espaços na instituição em que se encontram.

A experiência de atuação docente no estágio foi muito significativa durante a graduação, pois pude me conhecer como professora, pesquisadora e atuante na Educação Infantil, incorporando em minha prática os conceitos e leituras que fiz durante o curso. Além disso, nesse momento pude entender na prática como ocorrem os planejamentos, como se formam as relações, como se ensinam aos alunos.

Um dos desafios que havia me imposto para esse momento era a inclusão de conhecimentos musicais em minhas aulas. A partir do estudo de diversos autores da área da educação musical e da proposta de musicalização infantil de Josette Feres, me senti confiante para realizar atividades musicais com os bebês da turma do berçário. Percebi que mesmo 
quando as atividades não deram certo como eu havia planejado, pude aprender ao refletir sobre o erro e sobre a forma como cada momento se desenvolveu.

Penso que fui muito desafiada quando escolhi pesquisar e propor aos meus alunos as atividades que foram pensadas por essa educadora musical, pois ela propõe momentos de aula e atividades para crianças de oito meses de idade, acompanhadas dos responsáveis, aulas uma vez por semana com duração de trinta minutos, com instrumentos musicais disponíveis e no máximo oito alunos por aula. O contexto do estágio era muito diferente do proposto por Feres (1998). Eu fiz as atividades em uma sequência de dias, tinha vinte e três alunos com o acompanhamento de apenas eu e mais duas pessoas, com cinco horas por dia na presença dos alunos e sem instrumentos musicais disponíveis. Acredito que esse contexto diferenciado tenha contribuído para que algumas das atividades não tenham ocorrido da forma que havia planejado.

Ao refletir sobre todas as experiências vividas no estágio e sobre as atividades musicais realizadas com os bebês percebo que o professor pedagogo, se tiver interesse e buscar aprofundar seus conhecimentos, conseguirá incluir atividades e conteúdos musicais em suas práticas docentes. Acredito que isso proporcionará um ambiente mais lúdico, aprendizagens de forma mais agradáveis e permitirá que o aluno tenha contato com atividades e conteúdos da música, área do conhecimento muitas vezes percebida apenas como recreação ou ferramenta para auxílio de atividades de outras áreas do conhecimento.

Ao longo do artigo, busquei refletir sobre as práticas pedagógico-musicais vivenciadas no período do estágio. Acredito que a apresentação da proposta de Josette Feres, exemplificando momentos de uma aula de música e atividades musicais possíveis de serem realizadas pelos pedagogos com seus alunos, e a posterior análise e reflexão das atividades por mim realizadas, pode servir de inspiração para uma maior inserção da música na educação infantil.

\section{Notas:}

$1 \mathrm{O}$ termo será utilizado no feminino devido ao número de professoras mulheres ser maioria tanto no contexto de formação quanto no contexto da escola de educação infantil na qual foi realizada o estágio.

2 "Sonorizar histórias se constitui em tornar sonoro um enredo, ou partes dele, em fazer soar uma trama, seja por meio da voz ou de objetos e instrumentos. Nesse tornar sonoro, a utilização de sons ou de melodias passa a fazer parte da narrativa" (REYS, 2011, p. 70).

3 Centro de integração Empresa-Escola.

4 Trecho das reflexões escritas no diário de pesquisa. Todas as referências desse diário estarão transcritas no artigo em itálico.

5 "Alô Fernanda, bom dia Fernanda. Que bom que você veio gosto muito de você". Ritmo e melodia da canção na página 27 do livro "Bebê, música e movimento: orientação para musicalização infantil".

6 "Pela rua abaixo vai Dona Formiga: uma mão na testa e a outra na barriga" Ritmo e melodia da canção na página 33 do livro "Bebê, música e movimento: orientação para musicalização infantil".

7 "Palminhas, palminhas nós vamos bater, depois as mãozinhas pra trás esconder". Ritmo e melodia da canção na página 35 do livro "Bebê, música e movimento: orientação para musicalização infantil".

8 "Palma, palma, palma, pé, pé, pé, roda, roda, roda, caranguejo peixe é". Ritmo e melodia da canção na página 36 do livro "Bebê, música e movimento: orientação para musicalização infantil".

9 "Salta, salta, anda 4 passos. Bate palma, bate palma, bate palma assim". Ritmo e melodia da canção na página 40 do livro "Bebê, música e movimento: orientação para musicalização infantil". 
10 "Serra aqui, serra ali, lenhador e carpinteiro. Serra aqui, serra ali, serra o topo do pinheiro". Ritmo e melodia da canção na página 41 do livro "Bebê, música e movimento: orientação para musicalização infantil".

11 "Lá vai o papai com seu carrinho a passear. E a mamãezinha vai contente a cantar: tra-la-la-la-la-la-la. Bibi fonfon. Lá vai papai: bibi fonfon". Ritmo e melodia da canção na página 47 do livro "Bebê, música e movimento: orientação para musicalização infantil".

12 Posição de cumprimento e respeito feita pelos militares das Forças Armadas.

\section{REFERÊNCIAS}

BRASIL, Referencial curricular da educação infantil. Passo Fundo: Berthier; Prefeitura Municipal de Passo Fundo, Secretaria Municipal de Educação, 2008.

BRITO, Teca Alencar de. Música na Educação Infantil. São Paulo. Peirópolis, 2003.

CORREA, Aruna Noal. O brincar-musical no cotidiano dos bebês. 2012. p. 1-10

CORREA, Aruna Noal. Bebês produzem música? O brincar-musical de bebês em berçário. Tese (Doutorado em Educação) - Universidade Federal do Rio Grande do Sul, Porto Alegre, 2013.

COUTINHO, Angela Scalabrin. A prática docente com os bebês. Pátio: Porto Alegre, 2013. $(8-11)$

FARIAS, Simone Fidelis. O movimento corporal no contexto da educação infantil. Trabalho de Conclusão de Curso. Curso de Pedagogia. Universidade do Estado da Bahia. Salvador, 2009.

FERES, Josette S. M. Bebê: música e movimento: orientação para musicalização infantil. Jundiaí, São Paulo: J. S. M. Feres, 1998.

FLICK, Uwe. Introdução à pesquisa qualitativa. 3. ed. Porto Alegre. Artmed, 2009.

ILARI, Beatriz; AGNOLLO, Vivian Dell. O desenvolvimento do canto em crianças de 2 a 6 anos de idade. In: Anais do XIV Encontro Anual da ABEM, Belo Horizonte, 2005.

ILARI, Beatriz. Música na infância e na adolescência: um livro para pais, professores e aficionados. Curitiba: Ibpex, 2009.

JOLY, Ilza Zenker Leme. Música e Educação: reflexões sobre a importância da música nos processos educativos. In: SANTIAGO, Diana, BROOCK, Angelita, CARVALHO, Tiago (Orgs.). Educação Musical Infantil. p. 15-37. Salvador: PPGMUS. UFBA, 2011.

MARCELO GARCIA, Carlos. O professor iniciante, a prática pedagógica e o sentido da experiência. Revista Brasileira de Pesquisa sobre Formação Docente, Belo Horizonte, v.03, n.03, p.11-49, 2010.

OLIVEIRA, Débora Alves de. Musicalização na Educação Infantil. In: Educação Temática Digital, v. 3, n. 1, p. 98-108, Campinas, 2001. 
OLIVEIRA, Maria Marly de. Como fazer pesquisa qualitativa. 4. ed. Petrópolis. Vozes, 2012.

REYS, Maria Cristiane Deltregia. Era uma vez... Entre sons, músicas e histórias. Música na Educação Básica, v. 3, n. 3, p. 68-83, 2011.

WERLE, Kelly. Sonorizando histórias e discutindo a educação musical na formação e nas práticas de pedagogas. Música na Educação Básica, v. 3, n. 3, p. 84-95, 2011. 